\title{
HUMANITIES
}

CMAJ

ART

\section{Imagined interiors}

A $s$ a patient who recently received treatment for lymphatic cancer, an important aspect of understanding my condition was being able to visualize the internal forms my illness was taking. During treatment, my condition was described to me by various medical professionals. The descriptions varied greatly, and there was little visual information available. Drawing on conversations throughout my treatment, I created abstracted drawings that represented the interior mass I imagined. This body of work is titled Imagined Interiors.

\section{“My work focuses visually on the body and speaks to the issue of communication."}

Each of the drawings in this series is titled with fragments of conversation with various medical professionals and hospital staff. In revealing my interpretation of these descriptions, the work evolved into a commentary on the way that the medical system communicates with individuals who do not have a scientific or medical background.

I imagined these interior forms in three dimensions rather than two; thus, I moved from two dimensions into three to sculpt "Mass." The suspended form and taut woven contours illustrate the volume and weight I imagined. I stayed away from materials and colours that imitate and reference traditional medical illustration and models with the intention of

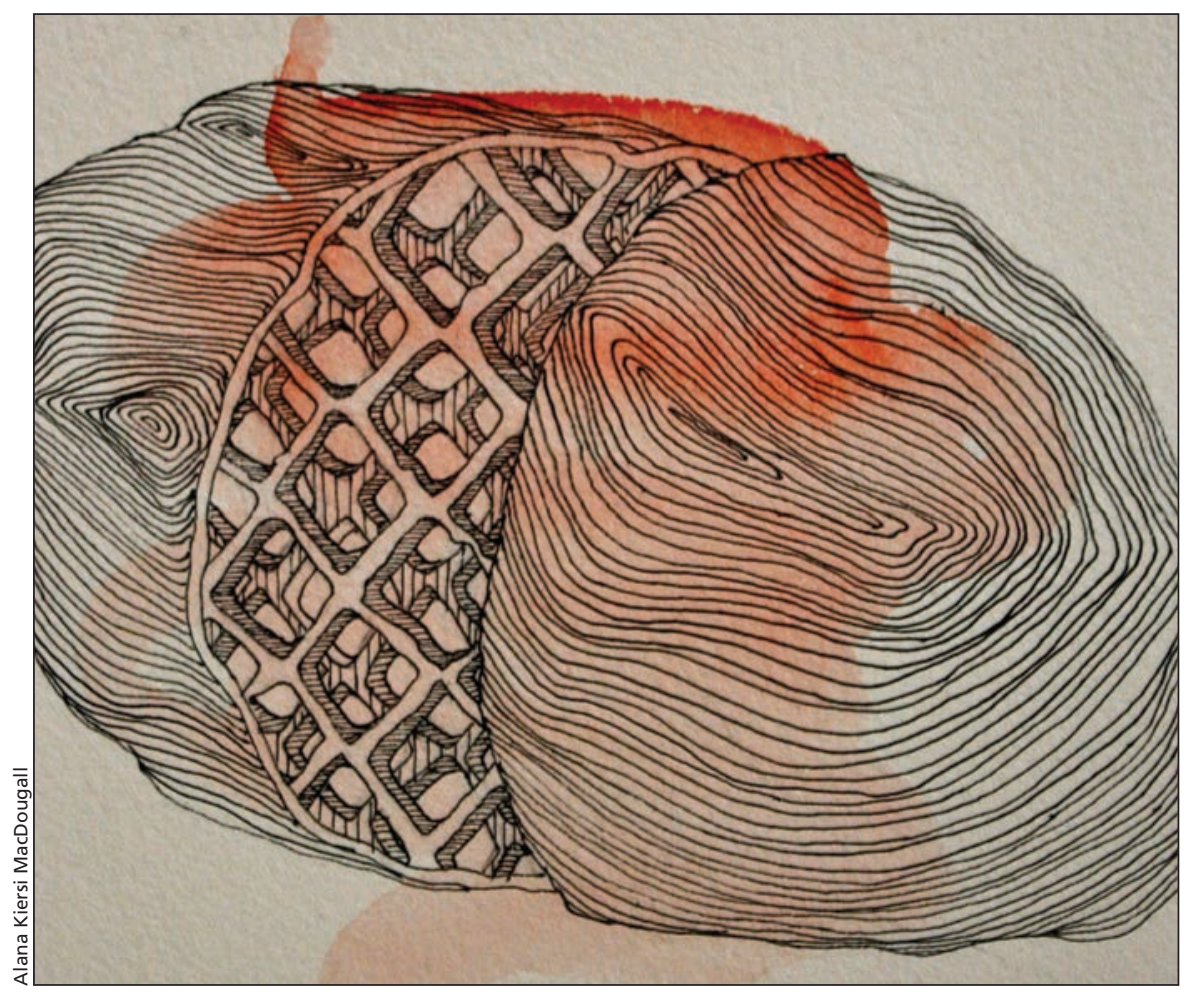

"I'd describe it as a mass of soft vascular tissue," 2013, by Alana Kiersi MacDougall. Ink and gouache on paper, 9" x 9".

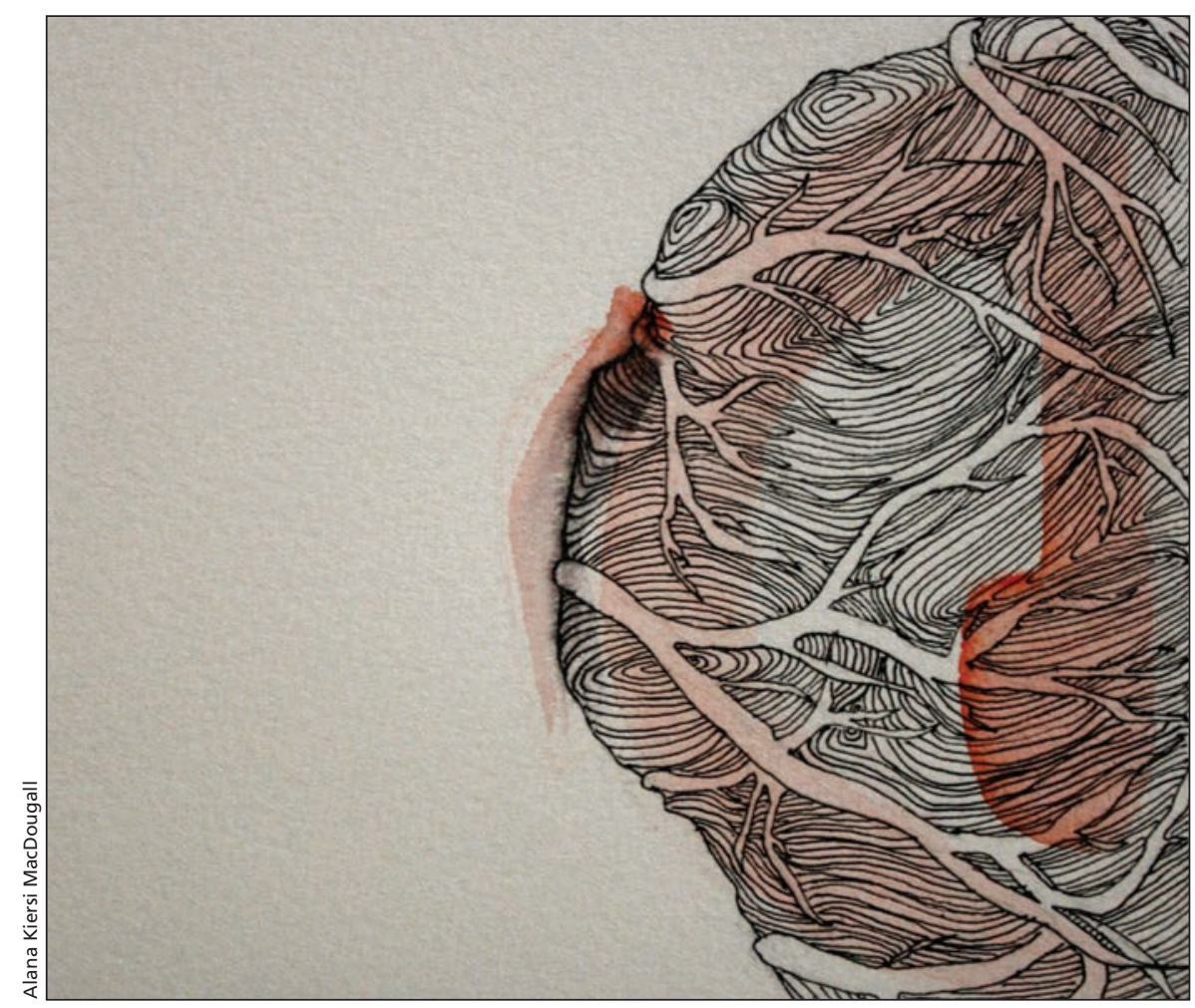

"These masses become so intertwined in a person's vascular system they are impossible to remove," 2013, by Alana Kiersi MacDougall. Ink and gouache on paper, 9" x 9". 
invoking a curiosity about the form, similar to the curiosity I felt about my condition.

The works of Imagined Interiors reference the art of Eva Hesse, who struggled with her health throughout her life. She received a diagnosis of brain cancer in 1969 and passed away a year later, ending a brief but vibrant artistic career. Hesse took a minimalist and material-driven approach to creating visceral sculpture and drawing. Although her work is not figurative in nature, she heavily referenced the body and organic forms.

Whereas many artists chronicle their illness and focus on their emotional journey, my work focuses visually on the body and speaks to the issue of communication. Although this series was created through the lens of a patient receiving treatment for cancer, the subject matter, communication within the medical system, relates to all aspects of health care.

The pieces are intended to allow viewers to think about their own experiences of how they understand changes to their bodies in the context of the health care system. The work was driven by a desire both to understand and to be understood, but also allowed me to relate to patients having similar experiences.

\section{Alana Kiersi MacDougall BFA \\ Visual artist \\ Winnipeg, Man.}

CMAJ 2015. DOI:10.1503/cmaj.140924

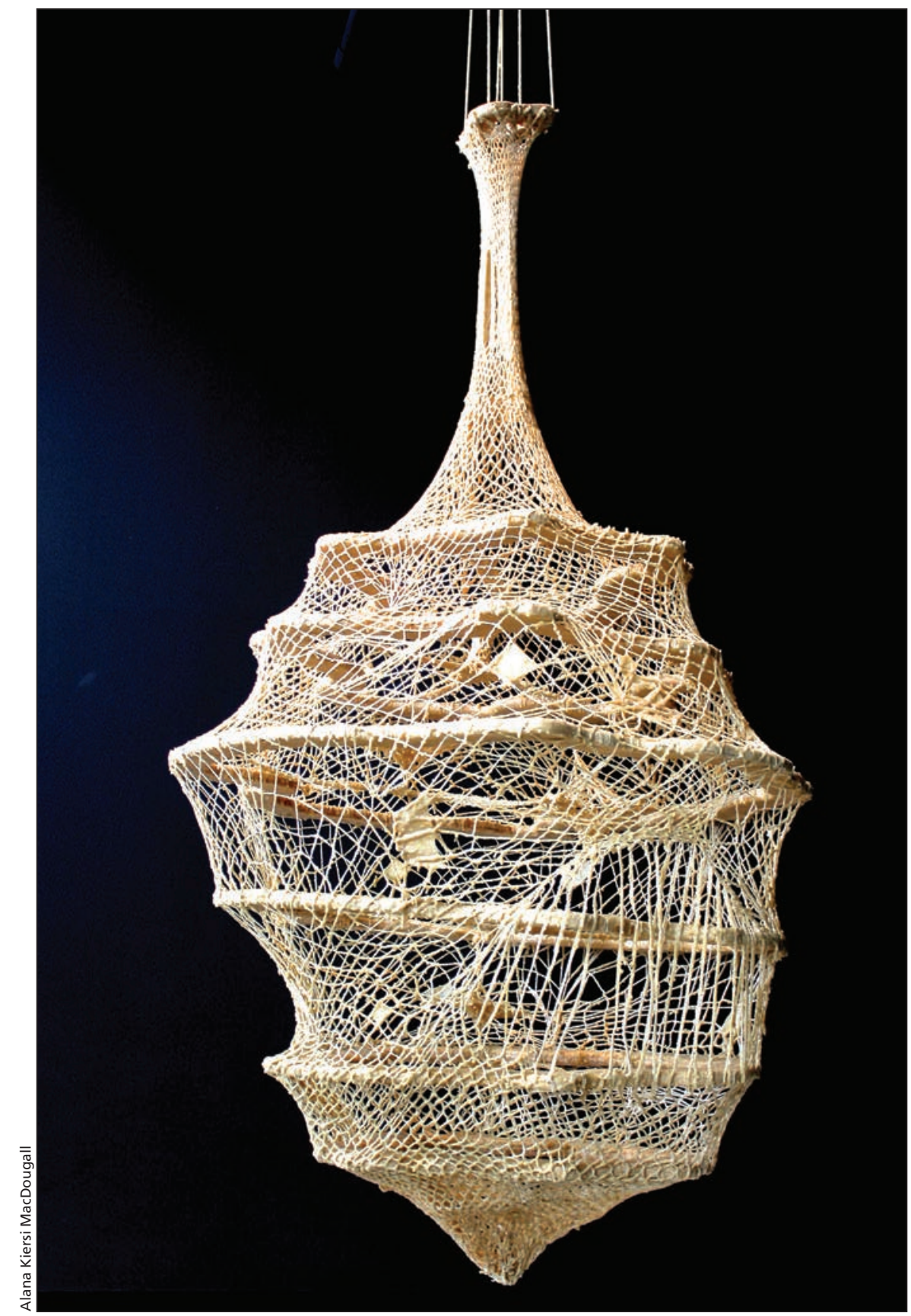

“Mass," 2013, by Alana Kiersi MacDougall. Wood, cotton string and beeswax, 3’ x 4' x 6’. 